\title{
Cerebral hemiatrophy associated with hematological and developmental disorders
}

\author{
Özkan Ünal ${ }^{1}$, Hüseyin Çaksen ${ }^{2}$, Nejmi Klymaz ${ }^{3}$, Imdat Dilek ${ }^{4}$, Mustafa Kayan $^{1}$, Ömer Anlar $^{5}$ \\ Departments of ${ }^{1}$ Radiology, ${ }^{2}$ Pediatric Neurology, ${ }^{3}$ Neurosurgery, ${ }^{4}$ Hematology, and \\ ${ }^{5}$ Neurology, Yüzüncü Yll University, Faculty of Medicine, Van, Turkey
}

\begin{abstract}
The etiology of cerebral hemiatrophy may be congenital or acquired. Trauma, infection, vascular abnormality, ischemic and hemorrhagic conditions may be the etiologic factors in acquired type. There is limited information about its association with other disorders in the literature. We presented three new cases of cerebral hemiatrophy associated with some hematological and developmental disorders. Cerebral hemiatrophy was associated with thalassemia major in a 10-year-old girl, acute myeloblastic leukemia and Marfan syndrome in a 23-year-old man, and craniosynostosis in a 1-year-old boy. To the best of our knowledge, thalassemia major, myeloblastic leukemia, Marfan syndrome and craniosynostosis have not been reported in cerebral hemiatrophy in the literature. (J Pediatr Neurol 2004; 2(3): 169-172).
\end{abstract}

Key words: cerebral hemiatrophy, thalassemia major, leukemia, craniosynostosis.

\section{Introduction}

Cerebral hemiatrophy $(\mathrm{CH})$ includes a heterogeneous group of pathologic entities with atrophy and impaired growth of one cerebral hemisphere. Dyke, Davidoff and Masson (1) described the findings on skull radiographs of ipsilateral calvarial thickening and overgrowth of

Correspondence: Özkan Ünal, M.D.

Yüzüncü Y1l University Faculty of Medicine

Department of Radiology, Van, 65200, Turkey.

Tel: +90 432 2168373, fax: +90 4322167519.

E-mail: ozkan_unal@hotmail.com

Received: January 21, 2004

Revised: February 23, 2004.

Accepted: February 23, 2004 the sinuses. Vascular insult that results in focal parenchymal destruction or prolonged seizure that results in diffuse and multifocal neuronal loss is associated with two proposed mechanism in the most series (2). This is associated with early unilateral large hemispheric ischemia or infarction, and usually due to the middle cerebral artery stroke. Radiological findings are very important in the diagnosis. Recently, several articles have described magnetic resonance imaging (MRI) and computerized tomography (CT) findings in $\mathrm{CH}$. However, there is limited information about its association with other disorders in the literature (3-6). In this article we reported three new cases of $\mathrm{CH}$ associated with some hematological and developmental disorders.

\section{Case Reports \\ Case 1}

A 10-year-old girl was exposed to right-sided paralysis since the age of 1 year. She was admitted to our hospital with the complaints of weakness, pallor and loss of appetite since 2 years old, which was increased recently. She was fully oriented. There was no background or hereditary disorder in her first degree-relatives. Right-sided hemiparesis, muscular atrophy on the right upper and lower extremities, spasticity, hyperreflexia, gingival hypertrophy, hepatosplenomegaly, and prominent frontal bones were noted on physical examination. Systolic murmur and thrill were diagnosed on cardiac examination. Laboratory examination showed high proportion of hemoglobin F, thrombocytopenia, severe anemia, elevated serum iron level and mild increased serum bilirubin level. Peripheral blood and bone marrow examination showed megaloblastic changes. Based on the clinical and laboratory findings the patient was diagnosed with thalassemia major. Cranial MRI was performed to explore the right sided hemiparesis, and $\mathrm{CH}$ was diagnosed due to atrophic and destructive changes in the whole left hemisphere, elevation of the left temporal bone, mild atrophy in ipsilateral cerebral 


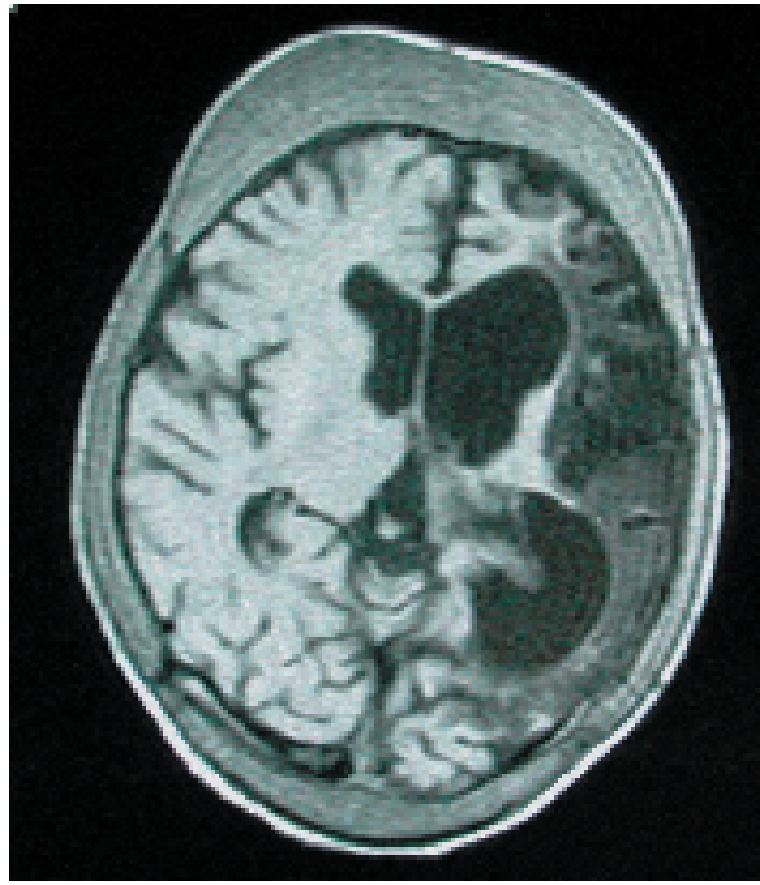

Figure 1. T1-weighted axial image shows left cerebral hemiatrophy and diffuse calvarial thickening in the first case.

peduncle and thalamus and contrlateral cerebellar hemisphere (Figure 1). Marked and bilateral skull thickening due to extramedullar hematopoesis was demonstrated. There was no difference between the calvarial sides for thickness. Other neuroimaging studies such as CT and angiography were not needed. The patient referred to a periodical erythrocyte transfusion and rehabilitation program.

\section{Case 2}

A 23-year-old man was admitted with malaise, pallor, nonproductive cough, weight loss, and night sweating. He had no history of exposure to toxic agents, smoking, use of alcohol or illicit drugs, or hereditary disorders in the first degree-relatives. Her general condition was poor, but he was fully oriented. His speech was slurred and mildly dysarthric. He had tall stature, thin and long face with intermaxillary narrowness, and paleness. The fingers were long and thin (arachnodactyly), and hyperextensible. He had large ear, bluish sclera, myopia-astigmatism, bilateral partial retinitis pigmentosa, gingival hypertrophy, mild scoliosis and pectus excavatum. Based on these abnormal findings Marfan syndrome was diagnosed. He also had mild hepatosplenomegaly, left hemiparesis, flexion contractures and muscular atrophy on the left upper and lower extremities. Babinski reflex was non-responsive on the left side. Peripheral blood sample and bone marrow examination showed that most of nucleated cells were blasts, which were compatible with acute myeloblastic leukemia

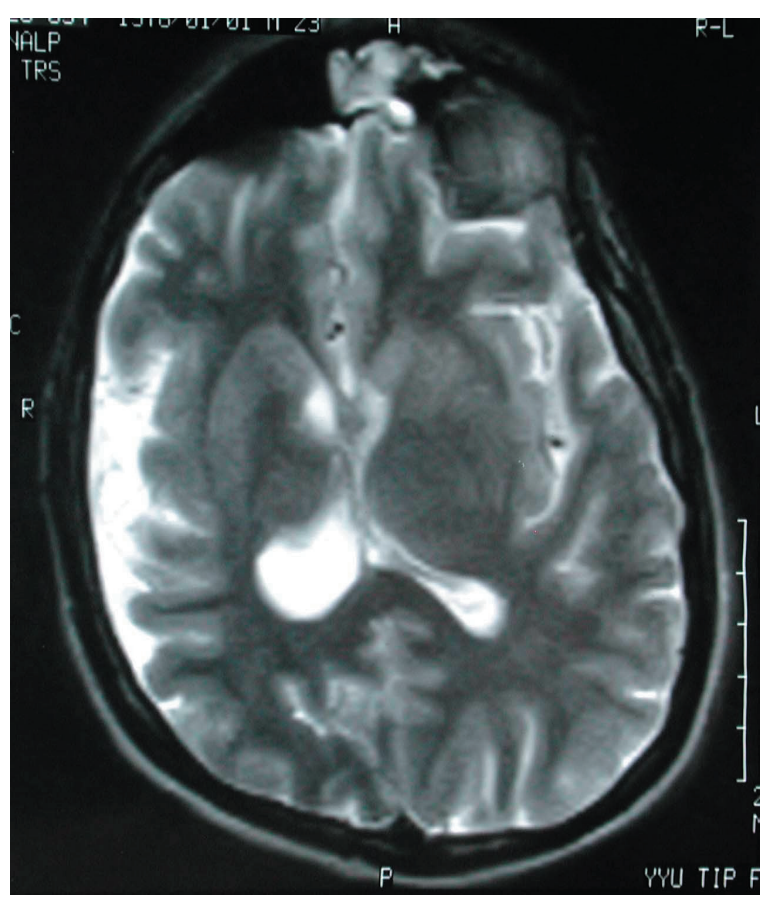

Figure 2. T2-weighted axial image shows left cerebral hemiatrophy in the second case.

(AML). Cranial MRI showed atrophy in the right cerebral and contrlateral cerebellar hemispheres, and mild enlargement of the ipsilateral calvarium (Figure 2). An arachnoid cyst $3 \times 1 \mathrm{~cm}$ a diameter was diagnosed in the right temporal lobe without mass effect. Packet red cells, platelet transfusion from a single donor and chemotherapy were given. The patient was discharged after the remission.

\section{Case 3}

1-year-old boy was suffering from inability to head control, unable to sit, microcephaly and growth retardation. He had a history of premature born. The family history was unremarkable. Physical examination revealed microcephaly (head circumference was $42 \mathrm{~cm}$, below the $3 \mathrm{rd}$ percentile), and motor and mental retardation. Cranial CT showed premature closure of lambdoid and coronal sutures. Calvarial thickness, mastoid air cells and paranasal sinuses were normal. MRI showed mild and diffuse cerebral hemiatrophy, and ventricular enlargement in the left side (Figure 3). The family did not allow a surgical intervention. He is followed in the outpatient clinic.

\section{Discussion}

The etiology of $\mathrm{CH}$ may be divided into two categories that are either congenital or acquired in nature. In the congenital category, there is usually no apparent causative factor. It is believed that the cerebral damage that is vascular in origin most 


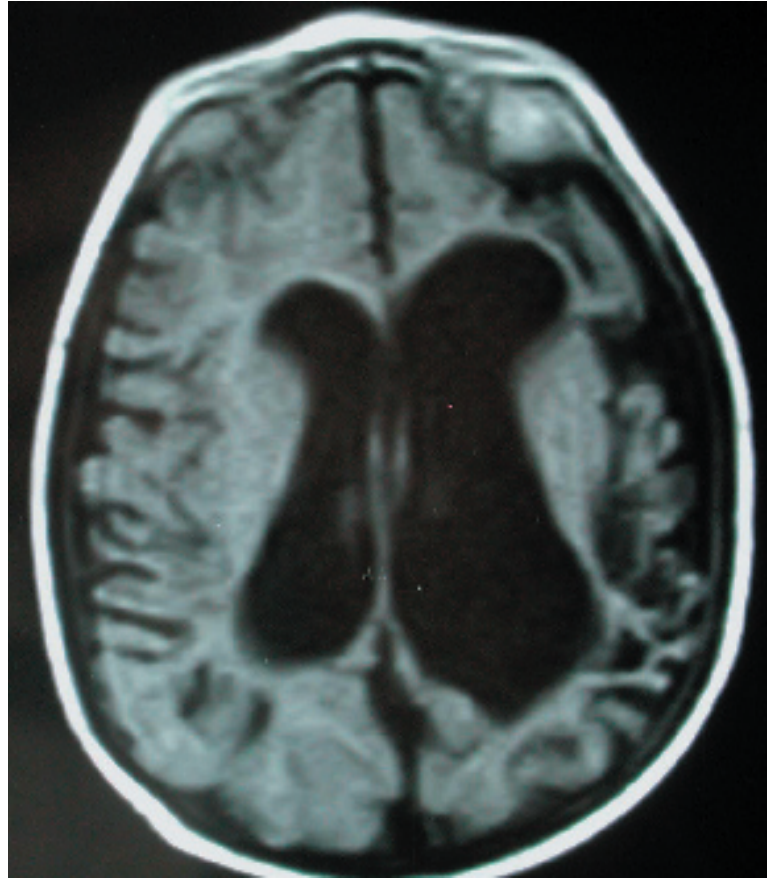

Figure 3. Lateral ventricular enlargement and cortical atrophy on the left side is seen on T2-weighted coronal image in case 3 .

likely occurs during intrauterine life, and the signs and symptoms are present at birth or shortly thereafter. In acquired type, the possible etiological factors are infection such as Rasmussen's encephalitis, trauma, vascular abnormality, and ischemic or hemorrhagic conditions. Hypoperfusion is usually the main factor in this syndrome $(7,8)$. Cerebral tumors should be included in the differential diagnosis of $\mathrm{CH}$, especially in the basal ganglia or internal capsule (9). Whatever the etiology is, the central nervous system injury must occur in the perinatal period or shortly thereafter, and thus before the calvarium and underlying neural tissue have achieved their full-term growth potential (10). We have not diagnosed any underlying disorders such as infection or trauma in our patients. However, we think that all of the patients might have encountered to other insults leaded to ischemia.

CT excellently evaluates bone changes. MRI represents the imaging procedure of the choice with respect to the assessment of the etiology and extent of cerebral parenchymal involvement. In addition, cerebral angiography may show attenuated small vessels on the ipsilateral side, but that finding doesn't necessarily imply a primary vascular occlusive etiology. A sickle cell disease and a growing skull fracture were reported in patients with $\mathrm{CH}(6,11)$. Stred et al. (4) reported an infant with coarctation of midaortic arch in association of left $\mathrm{CH}$. There are a few recorded instances of brain tumors with ipsilateral secondary brain atrophy in the literature $(3,5)$. Some of these patients needed hemispherectomy or some kind of surgical intervention. In our study none of the patients was performed a surgical intervention to $\mathrm{CH}$.

We described three cases of $\mathrm{CH}$ associated with thalassemia major, AML, Marfan syndrome and craniosynostosis. Thalassemia major is a homozygous dominant inheritance of defect of hemoglobin synthesis with increased production of hemoglobin F. Since it is well known that tromboembolic events are frequently observed in patients with thalassemia major, and it might lead to cerebral artery stroke in our case $(12,13)$. Marked and diffuse calvarial thickening are seen in thalassemia major. Although calvarial thickening is diffuse in thalassemia major due to extrameduller hematopoesis, it is unilateral and at the site of cerebral atrophy in $\mathrm{CH}$. The diagnosis of $\mathrm{CH}$ syndrome may be difficult in patients with thalassemia due to bilateral calvarial thickening

Marfan syndrome is an inherited disorder with characteristic ocular, skeletal and cardiovascular abnormalities, and effects the development of bone, ligaments, tendons, and arterial walls. Longevity of this syndrome is decreased because of the high percentage of cardiovascular complication. AML is also a disease of hematopoietic tissue and may develop from the progression of other clonal disorders of hematopoietic stem cells. Two sporadic cases of AML associated with Marfan syndrome have been reported in the literature $(14,15)$. The both AML and Marfan syndrome may be the etiological factors for the development of vascular occlusion in Case 2. However, onset of AML could not be old, because the progression of AML is usually very rapid. We think that these two different diseases might be coincidence.

Craniosynostosis is a premature closure of sutures, which results in skull abnormalities. It may be primary or secondary and may be a part of some syndrome, such as Antley-Bixler syndrome (16) or Pfeiffer syndrome (17). Unilateral calvarial thickening was not seen in Case 3. Due to the fact that craniosynostosis and thalassemia major affect cranial bones bilaterally, ipsilateral cranial thickening could not be observed in $\mathrm{CH}$ association with these disorders.

\section{References}

1. Dyke CG, Davidoff LM, Masson CB. Cerebral hemiatrophy with homolateral hypertrophy of the skull and sinuses. Surg Gynecol Obstet 1933; 57: 588-600.

2. Dix JE, Cail WS. Cerebral hemiatrophy: classification on the basis of MR imaging findings of mesial temporal sclerosis and childhood febrile seizures. Radiology 1997; 203: 269-274.

3. Maehara T, Machida T, Tsuchiya K, Iio M. Brain tumors with ipsilateral cerebral hemiatrophy. AJNR Am J Neuroradiol 1983; 4: 478-480. 
4. Stred SE, Byrum CJ, Bove EL, Oliphant M. Coarctation of the midaortic arch presenting with monoparesis. Ann Thorac Surg 1986; 42: 210-212.

5. Jayakumar PN, Rao TV, Arya BY, Jain VK. Hemiatrophy and glioblastoma. Surg Neurol 1987; 27: 291-294.

6. Shener RN. Growing skull fracture in a patient with cerebral hemiatrophy. Pediatr Radiol 1995; 25: 6465.

7. Nass R, Kramer E, Molofsky W, et al. Perfusion brain scintigraphy studies in infants and children with malformations of the vein of Galen. Child's Nerv Syst 2001; 17: 519-523.

8. Bien $\mathrm{CG}$, Widman $\mathrm{G}$, Urbach $\mathrm{H}$, et al. The natural history of Rasmussen's encephalitis. Brain 2002; 125: $1751-1759$.

9. Kim CH, Paek SH, Park IA, Chi JG, Kim DG. Cerebral germinoma with hemiatrophy of the brain: report of three cases. Acta Neurochir (Wien) 2002; 144: $145-150$

10. Zilkha A. CT of cerebral hemiatrophy. AJR Am J
Roentgenol 1980; 135: 259-262.

11. Şener RN, Jinkins JR. MR of craniocerebral hemiatrophy. Clin Imaging 1992; 16: 93-97.

12. Borgna Pignatti C, Carnelli V, Caruso V, et al. Thromboembolic events in beta thalassemia major: an Italian multicenter study. Acta Haematol 1998; 99: 76-79.

13. Sharief N, Kingston JE, Wright VM, Costeloe K. Acute leukemia in an infant with Marfan's syndrome: a case report. Pediatr Hematol Oncol 1991; 8: 323-327.

14. Lee JJ, Kim HJ, Chung IJ, et al. A case of Marfan syndrome with acute monoblastic leukemia. Korean J Intern Med 1998; 13: 140-142.

15. Hosalkar HS, Shah HS, Gujar PS, Shaw BA. The Antley-Bixler syndrome: two new cases. J Postgrad Med 2001; 47: 252-255.

16. Teebi AS, Kennedy S, Chun K, Ray PN. Severe and mild phenotypes in Pfeiffer syndrome with splice acceptor mutations in exon IIIc of FGFR2. Am J Med Genet 2002; 107: 43-47. 